\title{
SÍMBOLO, GEOMETRÍA Y FILOSOFÍA ORIENTAL EN LA ESCULTURA DE OTEIZA
}

\author{
María Belén León del Río \\ Universidad de Sevilla. Dpto. Escultura e Historia de las Artes Plásticas
}

\begin{abstract}
Resumen
Mediante la activación de los símbolos y la geometría de la escultura de Oteiza el espectador se pondría en consonancia con nuevos tipos de comunicación con su yo interior, lo que significará una transición hacia metas nuevas, donde el arte nos ayudaría a tener un discernimiento más profundo de nosotros mismos, abriendo nuestra mente a lo que estaría más allá de la consciencia. En este artículo veremos cómo la escultura de Oteiza tendría relación con nuestra historia evolutiva, presentando una simbología que no sólo recuperaría nuestro pasado mediante formas arquetípicas, sino que ya se estarían dando pasos en el descubrimiento de nuevos símbolos que tendrían también que ver con nuestro futuro evolutivo. Estos símbolos y arquetipos que subyacen en la geometría de su obra recuperarían la filosofía de Oriente teniendo una enorme importancia como armonizadores de nuestra existencia, mediante la aplicación de nuestras capacidades perceptivas e intuitivas.
\end{abstract}

Palabras clave: OTEIZA, JORGE (1908-2003); ESCULTURA; GEOMETRÍA; SÍMBOLO; ARQUETIPO; ZEN; CONSCIENCIA

\section{ORIENTAL SYMBOL, GEOMETRY AND PHILOSOPHY IN OTEIZA'S SCULPTUR}

Abstract

By activating the symbols and geometry of Oteiza's sculpture, the viewer would be brought into line with new types of communication with his inner self, which will mean a transition towards new goals, where art would help us to have a deeper discernment. of ourselves, opening our mind to what would be beyond consciousness. This article we will see how Oteiza's sculpture would be related to our evolutionary history, presenting a symbology that would not only recover our past through archetypal forms, but that steps would already be taken in the discovery of new symbols that would also have to do with our future. evolutionary. These symbols and archetypes that underlie the geometry of his work would recover the philosophy of the East, having enormous importance as harmonizers of our existence, through the application of our perceptual and intuitive capacities.

Keywords: OTEIZA, JORGE (1908-2003); SCULPTURE; GEOMETRY; SYMBOL; ARCHETYPE; ZEN; CONSCIOUSNESS

\footnotetext{
León del Río, María Belén. 2021. "Símbolo, geometría y filosofía oriental en la escultura de Oteiza". AusArt 9 (2): 145-165. DOI: 10.1387/ ausart.23006
}

\section{AUSART}




\section{LA ESCULTURA DE OTEIZA Y EL VACÍO EN LA FILOSOFÍA ORIENTAL}

Oteiza, hablando de su escultura y el proceso creativo que llevaba a cabo, afirmaba que a través de ésta se posibilitaría una consonancia con nosotros mismos a través de "una especie de respiración visual que nos permite sumergirnos en las cosas y en los acontecimientos del Espacio, enriqueciendo nuestra sensibilidad, ampliando nuestra libertad, asegurando espiritualmente nuestra existencia " (citado en Kortadi 2005: 48). Para Oteiza su arte experimental con la escultura estaría "entrando en una zona de silencio" (citado en Vega 2005 : 65), confesando que él mismo terminó entrando a través de su obra en un espacio vacío al que definía como 'nada' y cómo en este espacio el ser humano se afirmaría en su propio ser. En este sentido, autores cómo Sri Aurobindo señalan cómo el artista puede entrar en el silencio o vacío infinito, constituyendo una parte de la experiencia espiritual, además de ser "la condición necesaria para un conocimiento más grande, para un poder y una felicidad superiores" (Aurobindo [1909] 1999, 174), definiendo este vacío como una identificación con el Todo, como "una extensión de una consciencia de sí esencial, libre y pura..." (Aurobindo [1949] 2008, 164).

D. Chopra y M. C. Kafatos llaman la atención sobre cómo el vacío cuántico tendría grandes cantidades de energía y que el universo saldría del vacío cuántico, diciendo como "tampoco cabe dudar que, si nos remontamos en la historia del universo hasta su fase más temprana, debe intervenir en esta la física del vacío (cuántico)" (Chopra \& Kafatos 2017, 63). Según H. Weyl (1990, 102) el espacio vacío tendría una gran simetría, ya que "cada punto es igual que los otros, $y$ en un punto no hay diferencia intrínseca entre las diversas direcciones". Mientras que F. Wilczek (2018) se admira de cómo el espacio vacío sería "un conductor de muchas capas y multicolor". Este científico ha descubierto una abrumadora simetría de gran elegancia en la cromodinámica cuántica, cuando desarrolla sus ecuaciones maestras:

[...] obtenemos ecuaciones relacionadas por la simetría, simetría entre colores, simetría entre diferentes dimensiones espaciales, y la simetría de la relatividad especial entre sistemas que se desplazan a velocidad constante. Su contenido completo va por delante y los algoritmos que lo desarrollan fluyen a partir de las matemáticas no ambiguas de la simetría.

(Wilczek 2018, 84-5) 
Heráclito afirmaba que todo a nuestro alrededor estaba cambiando constantemente, existiendo un logos (proporción) que subyacería en la naturaleza, diciendo que, si escuchamos "al logos más que a mí mismo, es sabio admitir que en realidad todas las cosas son una misma cosa" (citado en Hemenway 2008 , 172). P. Hemenway interpreta este logos como el tao de Laozi o el rit de los sabios védicos:

La palabra sánscrita rit o rta se deriva de la raíz ar , que significa encajar perfectamente, juntarse sin fisuras, estar perfectamente unidos. El término rta remite a una rueda perfectamente equilibrada que gira rítmica y suavemente y que se asocia a la palabra griega harmos (armonía), así como al latín ars, que es la raíz de nuestro arte y artista.

(Hemenway 2008, 172)

A. Daniélou señala como el lenguaje visual de los símbolos se basaría en formas geométricas o yanträ que también se corresponderían con los fonemas del lenguaje hablado y con las relaciones numéricas de la música. Mediante sus conexiones matemáticas reflejarían las estructuras de la materia y los principios vitales además de expresar determinados estados del ser humano como las emociones o los sentimientos: "Los yanträ evocan las constantes que encontramos en la base de todas las estructuras del mundo, de los átomos y la galaxia, de los componentes de la vida y del pensamiento" (Daniélou [1935] 2012, 269). Según Sri Aurobindo el surgimiento de la mente en el ser humano al igual que el lenguaje, se hizo a partir de las actividades vitales y sensoriales edificándose el uso intelectual del lenguaje a partir de lo sensorial y lo emocional: "Tras haber consistido originariamente en emisiones vocales con un sentido vago y potencial, las palabras evolucionaron hasta convertirse en los símbolos fijos de una idea intelectual precisa" (Aurobindo [1921] 2001, 69). Antes de esta asociación simbólica las palabras "revistieron un cierto carácter cualitativo, guna susceptible de gran número de aplicaciones y que, por consiguiente, confería a cada una de ellas un gran número de significados posibles" (ibíd.), llamando la atención de cómo esta primera etapa donde se desarrolló el lenguaje, la palabra se comportaría como una 'fuerza viva' que estaría más viva incluso que su idea, ya que el sonido determinaría su sentido.

Para Oteiza las palabras tendrían un carácter emocional y simbólico, así arr (hueco) como uts (vacío), serían morfemas de origen protohistórico como el cromlech que el escultor dota de un revestimiento metafísico relacionado con el arte y el espacio además de proponerlas "como modelo de comportamiento artístico, social y religioso que debe recuperar el creador contempo- 
ráneo para curar con su solución estética la angustia existencial del hombre" (Álvarez 2003, 184). En su libro Quousque Tandem...! de 1963 hace una serie de reflexiones sobre "El cromlech vasco y el eusquera" señalando cómo el 'yo-cromlech' sería "la consciencia personal, en relación sagrada con lo Absoluto y los demás" (Oteiza 2021:40). Aseverando cómo debía conservarse en la lengua vasca un término que pueda designar al cromlech con la raíz uts, ya que de esta manera sería "más auténtico, directo y primitivo", frente a txadon que el escultor no identificaría con 'cromlech-iglesia' ya que sería un neologísmo que limitaría la religiosidad, siendo en cambio el término utsela más universal para un recinto religioso. La semántica sería entendida por Oteiza desde el significado de las palabras y los símbolos, ya que esta ciencia pasaría al significado del pensamiento y de las relaciones del ser humano "con su propio pensamiento y con el mundo, a la recuperación de la salud del pensar como proyecto para el comportamiento [...]" (citado en Álvarez 2003, 184).

\section{LA GEOMETRÍA DEL CÍRCULO EN LA ESCULTURA DE OTEIZA Y EL ZEN}

En la primera escultura de la serie titulada Par espacial ingrávido (Par móvil), realizada por Oteiza en 1956, vemos dos semicírculos que estarían "unidos por un punto de su diámetro no central, sino desplazado según la proporción áurea" (Badiola 2005, 199) , con esta obra el artista se plantea si esta escultura "podría moverse desde su estructura misma, por su propia decisión" (citado en Álvarez 2003, 152), el escultor la deja caer y la balancea buscando su estabilidad mediante un tercer punto que no logra encontrar a pesar del intento diciendo: "Pero la escultura seguía cautiva en la mano del hombre, el escultor unido a su estatua, los dos sin libertad [...]" (ibíd.). Según S. Álvarez, aunque la desocupación dinámica de la esfera que consigue con la serie Par móvil sería fundamental en sus investigaciones sería diferente como el propio Oteiza explica sobre la importancia del "vacío como resultado del espacio pasivo o sitio en espacio interno y transcendente" (ibíd.).

Para Oteiza el arte nos proporcionaría "la clave de un lenguaje en el que hablan también las formas de la experiencia sensible y diaria del espacio" (citado en Kortadi 2005, 46), diciendo cómo el escultor tendería a un proceso más radical y profundo donde se produciría una simplificación y depuración de formas que le llevarían a toparse "con las formas y figuras más simples del 
inconsciente humano: el punto, la línea, el cuadrado, el rectángulo, el triángulo y el círculo" (ibíd., 34). Oteiza, en su serie en acero forjado Desocupación de la esfera, de los años cincuenta, explica sobre este cuerpo geométrico que estaría "tan satisfecho y perfecto por dentro como inestable y ciego por fuera" (citado en Badiola 2005, 199), por lo que el artista decide abrir este volumen esférico para así corregir su ceguera. S. Álvarez señala como Desocupación de la esfera, o Conclusión experimental $n^{\circ} 2$ de las que Oteiza llevara a cabo dos versiones en 1958, se trataría "de una escultura en las que las bandas de hierro se curvan formando tres cilindros abiertos, cuyo carácter dinámico intrínseco a lo redondo se contrarresta y se inmoviliza con la barra cilíndrica que los fija a una base" (Álvarez 2003, 148). Estas esculturas serían interpretadas por el escultor como 'vacío crómlech' siendo "resultado espacial de un vacío redondo y protector, de un espacio metafísico" (Álvarez 2003, 148).

Oteiza afirmaba cómo habría tenido la intuición del vacío gracias al descubrimiento del cromlech "como estatua-cromlech, y en seguida la comprensión del vacío final en la pintura de Velázquez, la del vacío en la tradición artística oriental y la de algunos vacíos repentinamente involuntarios, en el arte contemporáneo" (Oteiza [1963] 2021, 98). Sus investigaciones espaciales sobre el círculo, la esfera, las rotaciones alrededor de un punto central o las espirales serán fundamentales en su obra, teniendo el círculo para el escultor un carácter sagrado que daría respuesta a una metafísica de la existencia del ser humano, además de tener una gran importancia en su cultura vasca, ya que en esta tradición "lo que se ha cerrado e inmovilizado en la imaginación del círculo es toda suerte estética y religiosa de una antigua experimentación de los comportamientos" (citado en Álvarez 2003, 148). Oteiza decía cómo el crómlech neolítico vasco "implicaba la respuesta a la interrogación sobre la definición de su Ser" (Arnaiz Gómez 2006, 317), afirmando que este círculo vacío no sería de uso doméstico o funerario, sino una construcción simbólica de carácter metafísico y espiritual que elevaría la consciencia del ser humano. Este pensamiento se resume en La estela del Padre Donostia situada en el alto de Agiña (Fig. 1), lugar de ritos y monumentos megalíticos elegido por Oteiza para enclavar su obra a la que describe como una piedra negra, tallada de forma cuadrangular con "un círculo vacío, ligeramente descentrado que lleva dos perforaciones por las que, en determinados momentos, la mañana y la tarde, depositará, puñados de luz" (citado en Arnaiz Gómez 2006, 320). El artista decía cómo la estela produciría en el espectador no solo un sentimiento de soledad y de una 'presencia distante' sino también la impresión de gravedad, la piedra flotaría sobre el 'suelo de cromlechs' que acompañarían al monumento: 


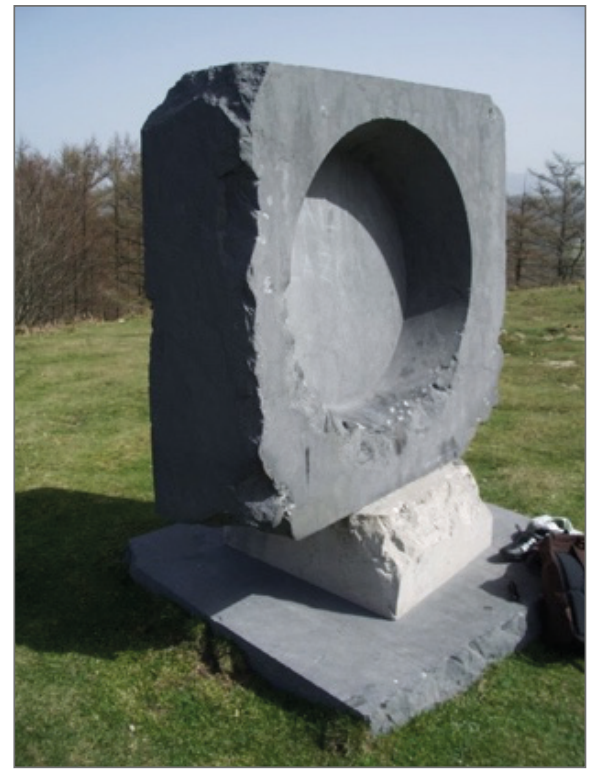

El simbolismo geométrico del círculo y del cuadrado, levemente desviado en ese señalado lugar, como un ancla en rotación incesante del paisaje, se quisiera que lo desocupe todo, que nos ignorase con la indiferencia de todo lo que es Bueno y Eterno, que nos haga rezar y sentir lo poco que somos.

(Oteiza en Arnaiz Gómez 2006, 320)

Fig. 1. Jorge Oteiza, Homenaje a Padre Donosti de 1957.

https://upload.wikimedia.org/wikipedia/commons/8/83/Agina_Lesaka_Oteiza_Aita_Donostia. JPG

Eduardo Pérez de Carrera señala cómo en la historia del ser humano se habrían construido configuraciones mandálicas que fueron modelo de marchas y bailes rituales, además de laberintos que eran recomendados por sus diseñadores "para convocar el adiestramiento del lóbulo cerebral izquierdo" (2004, 227). Las culturas megalíticas trazaron miles de meridianos sobre la superficie geográfica mediante filas de menhires de piedra especialmente buscada, además de dólmenes y puertas iniciáticas que todavía jalonan puntos estratégicos como si se tratara de "una misteriosa acupuntura de la Tierra" (ibíd., 31). Para este autor habría un paralelismo entre estas construcciones y la milenaria Medicina china que practicaría "el arte del conocimiento de los meridianos energéticos que recorren la fisiología humana, plantan agujas en partes estratégicas para estimular el flujo en los retornos y para eliminar obstáculos en la purificación de la inteligencia" (ibíd.).

En el lamaísmo y el yoga tántrico utilizarían la imagen del mandala para la activación de la imaginación del creyente mediante un círculo en cuyo alrededor o dentro del cual se encontraría un cuadrado o una figura religiosa, significando el cosmos como un todo unificado y organizado. Este símbolo tendría una pre- 
sencia fundamental en toda la historia del arte tanto oriental como occidental: "El mandala es la división del círculo de la unidad en las formas comprensibles del cuadrado, el hexágono, el octógono, el eneágono, etc..., y estas formas están consideradas como los primeros pensamientos de Dios, que surgen de la unidad circular". (Lawlor [1982] 1993, 17)

En La estela del Padre Donostia vemos la simbología de la 'cuadratura del círculo' que en la alquimia simbolizaría la identificación del cielo (círculo) con la tierra (cuadrado), unión que produciría una anulación de estos dos principios cósmicos en una síntesis superior, mediante la 'circulación del cuadrado' originándose la obtención de "la unidad de lo material (y de la vida espiritual) por encima de las diferencias y oposiciones (orientaciones) del cuatro y del cuadrado" (Cirlot [1958] 1969, 164-5). Este simbolismo sintético de lo material y lo espiritual, es descrito por Oteiza en referencia a la estela en su escrito titulado Ciegos en Plenilunio: Entendimiento de la geometría para la comprensión religiosa del arte, donde compara la imagen de su estela con "la forma religiosa del círculo con la del cromlech, con la Sagrada Forma de la Eucaristía y con los círculos del sol y el plenilunio" ([1995] 2017, 188). En este texto explica cómo el artista construiría "un sistema de señales en el espacio" (ibíd., 190), para poner en comunicación al ser humano con Dios mediante la vida y la intimidad de la consciencia, señalando la "relación agónica" que sufriría el hombre con su realidad exterior, siendo el artista el que trabajaría en contra de esta situación relacionada con la muerte, la cual aparecería enmascarada a través del dolor, el miedo, la angustia existencial, la limitación de conocimiento y la ausencia de libertad. A través de la naturaleza espacial de la creación artística se podría luchar contra esta situación que se concretaría "con el Tiempo que empuja y mueve las formas y la vida hacía la muerte" (ibíd., 189). En este acto de transcendencia el creador plástico se aliaría con los entes geométricos que serían intemporales, inmovilizando así el espacio y "separándolo del tiempo, borrándolo de su realidad, que se define por un silencio espacial y receptivo que es la naturaleza precisamente de lo abstracto. Este concepto de lo abstracto es, desde lo estético, el Espacio religioso" (ibíd.).

El escultor llamaba la atención de cómo el arte de su tiempo estaba "entrando en una disciplina de silencio y eliminaciones, para desembocar en un nuevo vacío" (Oteiza [1963] 2021, 77), señalando que el arte primitivo oriental finalizaría en el concepto espiritual del espacio vacío que todavía conservaría su tradición religiosa. Lao Tse en su libro Tao Te King (ca 300 a.C. [1998], 21) describe la experiencia del vacío mediante ejemplos sencillos de la vida diciendo: "El Tao es como una taza vacía que, al usarse, nunca se puede llenar". El maestro 
en su libro Hua Hu Chig (ca 300 a.C. [1996], 15) nos enseña el 'Camino integral' para llegar a la unidad con el Tao diciendo cómo sus enseñanzas serían simples, pero de gran profundidad, conteniendo "toda la verdad del universo". En su libro Wen-Tzu escribe que cuando nuestros deseos de la vida dejan de ser un fardo para la persona se produciría "la consumación del vacío" (ca 300 a.C. [1995], 37), afirmando que cuando nuestra realidad externa es controlada por el centro la podemos gobernar: "Con el logro del centro, los órganos internos están en calma, los pensamientos son ecuánimes, los nervios y los huesos son fuertes, los oídos y los ojos están claros" (ibíd.). Según P. Cabañas Moreno y M. R. Arias Estévez, el vacío zen sería una experiencia de vaciedad que liberaría "nuestro yo y nuestros apegos" (Lao Tse citado en Cabañas \& Arias 2020, 173). De esta manera, al liberarnos de nuestro yo, podemos "abrirnos a la comprensión intuitiva del ser en la infinitud del universo" (ibíd.).

C. G. Jung nos introduce en este proceso psicológico que define como "proceso de individuación", un camino evolutivo que tendría que ver con la búsqueda de nuestro ser esencial o "sí-mismo", que sería transcendente a la consciencia como el atman bindú, poseyendo una existencia personal y cósmica y que expresaría la totalidad de la psique en todos sus aspectos, incluida la relación del ser humano con el conjunto de la naturaleza: "Es, como concepto esencial de la unión total de los opuestos, el 'símbolo unificador', y sólo puede ser expresado, conforme a su naturaleza paradójica, mediante figuras simbólicas" (Jung [1946] 1993, 131-2). Autores como J. Macareno Ramos relacionan el arte de Oteiza con el inconsciente de C. G. Jung haciendo un "paralelismo experiencial/vital entre los dos autores a través de sus respectivos ¿laboratorios experimentales? y sus diferentes tránsitos hacia la colectividad" (Macareno Ramos 2017).

Según C. G. Jung los símbolos del 'sí-mismo' emergerían de manera empírica en los sueños, fantasías y en el quehacer artístico, hallando su expresión en los temas mandálicos, como podemos comprobar en el budismo zen, donde el 'vacío vivo' se puede experimentar mediante el dibujo en tinta china del círculo o ensō. En esta técnica el pincel se debe mover con la mano y el codo levantados y sin el apoyo y movimiento de los dedos teniendo la tinta un significado simbólico de plenitud, mientras que el papel representaría el vacío. Shitao en su tratado (citado en Cabañas \& Arias 2020, 204-5) señala cómo hay que dejar la muñeca suelta o 'vacía' para que, de su movimiento, ya sea firme, ligero, derecho o acelerado, nazca una variedad de metamorfosis que engendraran "Io imprevisto y lo extraño; sus excentricidades hacen milagros, y cuando la muñeca está animada por el espíritu, ríos y montañas hacen don de su alma". 
Según G. Dorfles en la caligrafía zen, consistente en el trazado de un ideograma, el gesto tendría que ver con un "mecanismo particular que es dado por el 'ritmo interior' del organismo y no por el ritmo impuesto desde fuera..." (Dorfles 1969, 89). Una de las particularidades de esta técnica, sería que en este acto se produciría un devenir no sólo automático, sino también se produciría un automatismo distinto de la consciencia racional (vijnana), identificándose con la consciencia irracional (prajna), cuyo mecanismo "no es demostrable sino perceptible sólo autoceptivamente y que forma parte, por tanto, del elemento cinestésico, del más íntimo mecanismo psico-físico del individuo" (ibid., 88). G. Dorfles relaciona esta manera de obrar del calígrafo zen japonés con la poesía y la pintura, donde según este autor se produciría una atemporalidad, el logro del acto se produciría por 'fulguración' (satori), el mecanismo quedaría incorporado a la propia constitución del discípulo ‘a su Leib’ (ibíd., 89).

C. G. Jung busca analogías en la mística oriental y occidental para describir el proceso de individuación, poniendo de ejemplo los koans del budismo Zen, que aclararían al discípulo las relaciones entre el yo y el 'sí-mismo', al igual que San Juan de la Cruz que describe esta vivencia en La noche oscura del alma donde el místico expresa su búsqueda ardientemente de la divinidad que ansía la unión con Dios:

\section{En una noche oscura}

Con ansias en amores inflamada, ioh dichosa ventura! salí sin ser notada, estando ya mi casa sosegada.

A oscuras, y segura

por la secreta escala disfrazada,

joh dichosa ventura!

a oscuras y en celada, estando ya mi casa sosegada.

(San Juan de la Cruz, ca 1583)

Oteiza en su libro Existe Dios al noroeste en su capítulo titulado Introducción como soledad de Dios afirma cómo sería su soledad de lo divino lo que le impulsaría a la creación, explicando cómo al hombre se le expulsaría del paraíso para poner luz y amor en este mundo terrenal que se encontraría en descomposición, escribiendo: "Una teología primera de la soledad, luego una teología del hombre, una antropología del amor, una bonita lección en esta 
basura en el mundo del hombre (qué dices, Dios, Dios mío ¿Por qué te escondes?" (Oteiza [1990] 2019, 115).

Oteiza confiesa cómo en su experiencia personal con su obra, se habría producido un cambio en su concepción del arte, que habría pasado de ser una ciencia de la naturaleza para convertirse en una ciencia del espíritu, debido a "una reflexión estética en el hueco de la estatua como desocupación espacial, que me dejó con un espacio solo y aislado en la mano. Me quedaba sin estatua, pero estrenando vida" (Oteiza [1963] 2021, 98). De esta forma su arte deja de ser una actividad permanente para convertirse en un compromiso "en una urgencia existencial, para elaborar una sensibilidad espiritual para la percepción y dominio de la realidad y la vida" (ibíd.).

Sri Aurobindo afirma cómo el arte pertenecería al espíritu y no sería solamente un logro de la técnica, constituyendo "la encarnación de la verdad imperecedera de la belleza aprehendida en su realidad interior, en su divina felicidad, en su llamada a la suprema fuente del éxtasis, al Ananda" (Aurobindo [1949] 2002, 163). Este autor relaciona el arte con 'Ananda' o el gozo de ser que sería la fuente de toda existencia, ya que la existencia tiende y buscaría abierta o secretamente este gozo a través de todas sus actividades. Para Sri Aurobindo en la espiritualidad se encontraría el objetivo supremo, nuestra esperanza de perfección, esta espiritualidad abarcaría no sólo la actividad de la razón, sino también la estética, la ética, la vitalidad e incluso la corporalidad del ser humano y "su aspiración al conocimiento, su atracción por la belleza, su necesidad de amor, su impulso hacía la perfección, su demanda de poder y plenitud para la vida y el ser" (ibíd., 210). En este sentido Oteiza afirmaría cómo existiría una relación entre el ser estético y el Ser divino, diciendo que la religión, la metafísica y la estética a pesar de ser tres ciencias distintas constituirían una sola disciplina que tendría que ver con la relación del ser humano con Dios, estando el arte de su época comenzando un nuevo camino donde el artista tendría la responsabilidad de dar razón y una solución estética a su propio tiempo, y también a Dios, de manera que "el artista también se salva o muere eternamente" (Oteiza [1952] 2007, 249).

En la concepción de su escultura Oteiza concebiría el espacio desocupado, esto es, estéticamente vacío, o según lo denomina espacio crómlech, como un "espacio espiritualmente habitable para reflexión de la consciencia íntima, como silencio, como incomunicación expresiva con la naturaleza exterior, para el contacto o comunión directa con Dios" (citado en Kortadi 2005, 51). El escultor busca una geometría euclidiana, como dice E. Kortadi, donde también 
encontramos "un concepto de la plástica zen y del vacío oriental como jamás se haya visto. Oteiza potencia y radicaliza el cubismo-suprematismo europeo para conectar con la mejor tradición de los jardines y espacios acotados chinos" (Kortadi 2005, 41). Esta dimensión metafísica y espiritual de la realidad la podemos encontrar en obras como Homenaje al estilema vacío de cubismo / Momento espiritual, obra original de 1959 que fue posteriormente ampliada para ser colocada en el parque Yamaguchi (Pamplona) en 1997 (Fig. 2). En esta obra Oteiza combina estructuras con triedros y diedros diciendo:

Lo que tengo es Naturaleza, lo que me falta no es Naturaleza, la traspaso. He terminado mi escultura experimental cuando he logrado vaciar este hueco en el espacio natural, cuando he desocupado formalmente la estatua convirtiéndola en un mueble metafísico, en un espacio interior receptivo, espiritualmente habitable. La Naturaleza vuelve a mí.

(Oteiza citado en Kortadi 2005, 46)

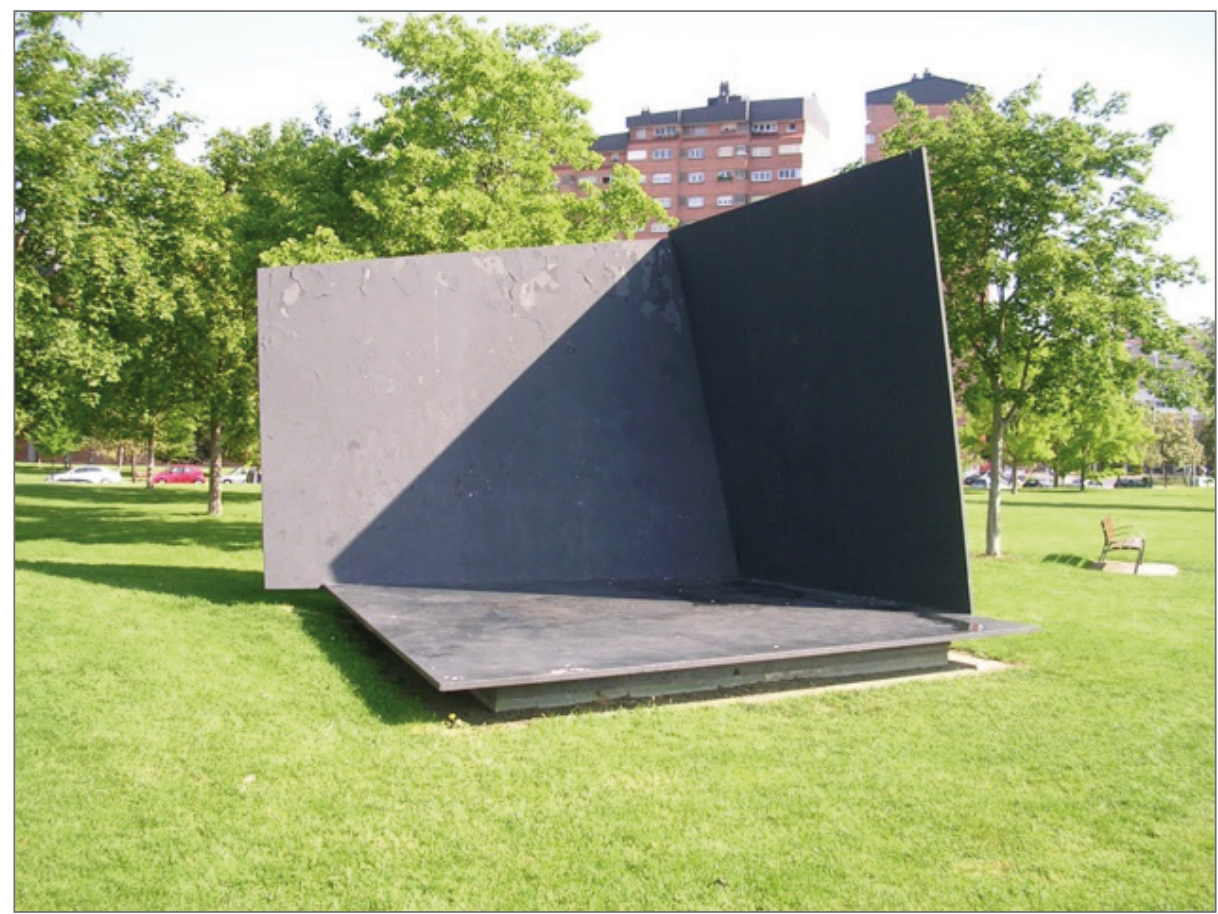

Figura 2. Jorge Oteiza Homenaje al estilema vacío de cubismo / Momento espiritual, Obra original de 1959. Ampliación en Yamaguchi Park (Pamplona). San Sebastián de 1997.

https://upload.wikimedia.org/wikipedia/commons/thumb/a/a0/Oteiza_Yamaguchi.jpg/1024px-Oteiza_Yamaguchi.jpg 
Oteiza cerrará con las Cajas vacías y las Cajas metafísicas una fase experimental comprendida entre 1958 y 1959 donde "se debilita la actividad formal, concentrándose en el dinamismo plástico en torno al núcleo interior vacío" (Álvarez 2003, 156). En su escultura titulada Caja metafísica con conjunción de los triedros realizada entre 1958 y 1959 vemos dos triedros, esquema composicional geométrico que llevará a diferentes versiones como (Uts-goika o Vacío de arriba) que el autor define como un 'retrato religioso', siendo estas obras para el propio artista construcciones simbólicas y de protección espiritual. Según S. Álvarez $(2003,77)$, Oteiza concibe la misión del artista como atestiguan sus textos teóricos como una verdadera aportación social que estaría al servicio de la espiritualización del individuo, siendo el arte una expresión transcendental de lo estético que daría al ser humano la clave de su necesidad de llegar a lo Absoluto, a Dios, declarándose el propio escultor como un 'obrero metafísico' que terminaría "su escultura experimental cuando logra vaciar el hueco en el espacio natural". En el epilogo del libro Consejos a un recién muerto de E. Amézaga de 1965 hace referencia a su Caja vacía, creación que compara con una 'muerte vacía', a la que define como una experiencia entre la vida y la muerte que se puede vivir a través de la escultura y cómo el mismo había sentido ese instante en el que se pierde del todo para llegar a ser 'no-ser': "Entro en un no-ser, en una resonancia de nuestra propia desocupación, en un silencio entero, independiente, suelto de todo, absoluto" (Oteiza [1995] 2017, 63).

E. Pérez de Carrera $(2004,221-2)$ señala cómo el arte movería nuestras geometrías estáticas, dinamizando nuestro mundo geométrico holográfico, además de crear espacios nuevos en nuestra estructura neuronal, diciendo que: "En los cruces de todas las corrientes (energías) que circulan por los llamados espacios vacíos del organismo están escritos muchos de los pasos que conducen el estado de experiencia al estado de esencia".

\section{LA ESCULTURA PÚBLICA DE OTEIZA Y LA UNIÓN DE LOS CONTRARIOS COMO TRANSFORMADOR SOCIAL}

Sri Aurobindo afirma cómo nuestro ser, consciencia y conocimiento se desplazarían entre dos estados o poderes velados de nuestra existencia ordinaria que serían "el del Infinito intemporal y el del Infinito que se despliega en sí 
mismo y organiza todas las cosas en el tiempo" ([1921] 1980, 262). Para nuestra lógica mental estos dos estados se opondrían siendo incompatibles debido a "una falsa concepción de contradicciones y una confrontación de eternos opuestos" (ibíd.). Mediante un conocimiento basado en la identidad, vemos en cambio que estos dos estados serían solo uno, tratándose de "un movimiento coexistente y concurrente de la misma verdad del Infinito. El Infinito Intemporal, en su verdad eterna del ser, más allá de esta manifestación, retiene en sí todo lo que se manifiesta en el Tiempo" (ibíd.). Mediante esta experiencia de autoconocimiento, nuestro sentido de la existencia separada desaparecerá en "una consciencia del ser ilimitable, indiviso e infinito" (Aurobindo [1921] 2005, 152), ya no estaríamos separados de nadie ni de los demás seres, viviendo en una nueva consciencia que nos libera y nos hace vivir en nuestro verdadero yo:

Esto fue lo que los antiguos pensadores llamaron el No-nacimiento o la destrucción del nacimiento o Nirvana. Al mismo tiempo continuamos viviendo y actuando a través de nuestro nacimiento y devenir individual, pero con un conocimiento diferente y un género muy distinto de experiencia; el mundo también continúa, pero lo vemos en nosotros mismos.

(Aurobindo [1921] 2005, 152)

Esta misma idea aparece en el vacío taoísta donde existiría esta polaridad de fuerzas yin y yang, donde gracias al juego de estas dos tensiones se produciría la armonía de la naturaleza. Zhuāngzi dice: "Quien alcanza su virtud primitiva se identifica con el origen del universo y, por él, con el vacío" (citado en Cabañas \& Arias 2020, 171), indicando cómo el vacío sería grande y lo compara con "un pájaro que canta espontáneamente y se identifica con el universo" (ibíd.). Para Lao Tse la encarnación del Tao tendría que ver con la aceptación de todo, lo cual significaría la unidad de los opuestos que estaban en conflicto, siendo la división contraria a la naturaleza del Tao: "Aceptarlo todo también significa apartarse de cualquier concepto de separación: hombre y mujer, yo y otro, vida y muerte" ([ca 300 a.C.] 1996, 17).

R. Lawlor señala que la corriente principal del hinduismo se habría basado en la noción del uno o de lo divino el cual se dividiría "dentro de sí mismo para formar su opuesto creándose a sí mismo, el universo manifestado. Dentro de la divina mirada a sí mismo, tres de sus propias cualidades se hicieron distintas: Sat (ser inmóvil), Chit (consciencia-Fuerza) y Ananda (éxtasis)" (Lawlor [1982] 1993, 21). Según este autor esta unidad original se representaría mediante la imagen del círculo que se reafirmaría por el pensamiento de Dios llamado 
semilla (bindu) que en occidente equivaldría a el punto geométrico. Este mismo concepto aparecería en las reflexiones de Oteiza sobre las etapas del proceso escultórico del constructivismo vasco en Cartas al príncipe cuando dice:

[...] el proceso experimental se produce en una $2^{\circ}$ fase complementaria de la 1. a fase cóncava, receptiva, procede por desocupación espacial hacía el silencio conclusivo de la expresión en este espacialismo geométrico la aventura no se inicia con el punto, concluye en un punto arranca del espacio en 3 dimensiones retrocediendo por el plano a la línea y finalizando en el saber espacial de un punto polidimensional y metafísico.

(Oteiza 1988, 49)

A. Daniélou señala cómo en toda manifestación partiría de una localización o de un punto del cual comenzaría su extensión, así en "el lenguaje de los yanträ, el punto (bindu) representaría el camino de lo no manifiesto a lo manifiesto" (Daniélou [1935] 2012, 269). Para este autor en todos los aspectos de la creación el "principio divino es aquello en lo que coexisten los contrarios" (ibíd., 272). Según Sri Aurobindo habría un fin común de la humanidad que consistiría en encontrar algún punto común o principio de unidad que reconciliara los contrarios. Para lograr esto de forma verdadera, el alma debe descubrir su realidad espiritual más elevada y completa, efectuando una transformación progresiva y ascendente de sus valores vitales en valores del espíritu:

[...] ahí todos esos valores encontrarán su verdad espiritual, y, en esa verdad, el punto común de su reconocimiento mutuo y su reconciliación. La verdad espiritual es la verdad única de la que todas las demás son aspectos velados brillantes disfraces u obscuras desfiguraciones, $y$, en ella, todas esas verdades parciales pueden encontrar su forma justa y sus mutuas relaciones verdaderas.

(Aurobindo [1949] 2002, 243)

Esta identidad de los principios contrapuestos fue una constante en la obra de Oteiza cómo podemos ver en su Laboratorio experimental (1948-1958), donde investiga a través de sus pequeñas maquetas a las que llamó familias experimentales toda clase de agrupaciones espaciales cómo "módulos de luz, sólidos abiertos, encadenamientos en el espacio, estructuras lineales, puntos en el espacio, puntos en movimiento, puntos vacíos, maclas, maquetas de luz, construcciones vacías, poliedros abiertos, desocupación de la esfera, etc." (Badiola 2004, 279), que más tarde llevará a su escultura pública como un elemento de transformación social de carácter religioso y salvador, expli- 
cando que en el proceso de creación escultórica el primer factor o grupo de elementos que entraban en acción era "el espacio y las formas de la realidad sensible, el material y el sitio con el tema exterior" (Oteiza citado en Kortadi $2005,45)$, después entraba inmediatamente en juego un segundo grupo ideal que el artista resumía "en una geometría de la composición o concepto de estructura que se toma de las ideas propias del tiempo en que uno vive y con la intención que la misma obra desde su emplazamiento en la arquitectura y en el paisaje, nos sugiere" (ibíd., 45-6). Finalmente, Oteiza enfrentaba estos dos elementos diciendo:

Hago chocar estos dos grupos de seres espaciales, el primero sometido al tiempo de la realidad, el segundo intemporal. El resultado es un material de naturaleza abstracta, un dominio espacial estéticamente valioso que vamos a utilizar como trampa para citar y reducir a estatua, al tiempo vital o de nuestra vida interior, origen de nuestra angustia existencial y objeto metafísico del arte.

(Oteiza citado en Kortadi 2005, 46)

En los escritos de Oteiza encontramos en relación con al arte gran cantidad de referencias sobre la unión de los contrarios cómo vemos en su libro Interpretación estética de la estatuaría megalítica americana de 1952, donde realiza una serie de descripciones sobre la magia del paisaje y de la estatuaria prehistórica del pueblo de San Agustín, situado en el enclave andino del Alto Magdalena. En este texto nos presenta este 'Paisaje' como si fuera "un cuerpo múltiple y sensible, cargado de misteriosas energías y que rueda fatalmente sobre nosotros con la clave de nuestro propio destino" (Oteiza [1952] 2007, 101). Oteiza encuentra en esta obra estática, una dualidad compuesta por "Io quieto-lo móvil" que contrasta con un paisaje donde se distingue un "choque estético" entre las dos caras de la naturaleza, en la que podemos ver el rostro quieto de las esculturas, en contraposición con el rostro móvil de las cosas externas, surgiendo de este encuentro "una especie inmóvil de seres que quedan fuera de la muerte. Queda así anticipado, de modo más simple, la categoría sobrenatural, la síntesis esencial -mágica- de cualquier producto artístico" (Oteiza [1952] 2007, 102).

G. Bachelard señala en su obra La poética de la ensoñación $(2019,263)$, cómo la imagen cósmica llevaría al poeta a la unidad del mundo, siendo una imagen primigenia de donde nacerían las demás imágenes que no se contradecirían, ya que "el soñador del mundo desconoce la división de su ser". El poeta, a través de la imaginación transformaría la imagen que percibiría en "un signo del mundo" (ibíd., 262). De manera que mientras que los pensadores tendrían que 
recorrer un gran camino a través de la reflexión, el poeta mediante la ensoñación imaginaria del mundo llegaría a una imagen cósmica inmediata:

Nos da el todo antes que las partes. En su exuberancia cree decir todo del Todo. Se apodera del universo por uno de sus signos. Una sola imagen invade todo el universo difundiendo en todo él la felicidad que sentimos por habitar en el mundo mismo de esta imagen.

(Bachelard 2019, 262)

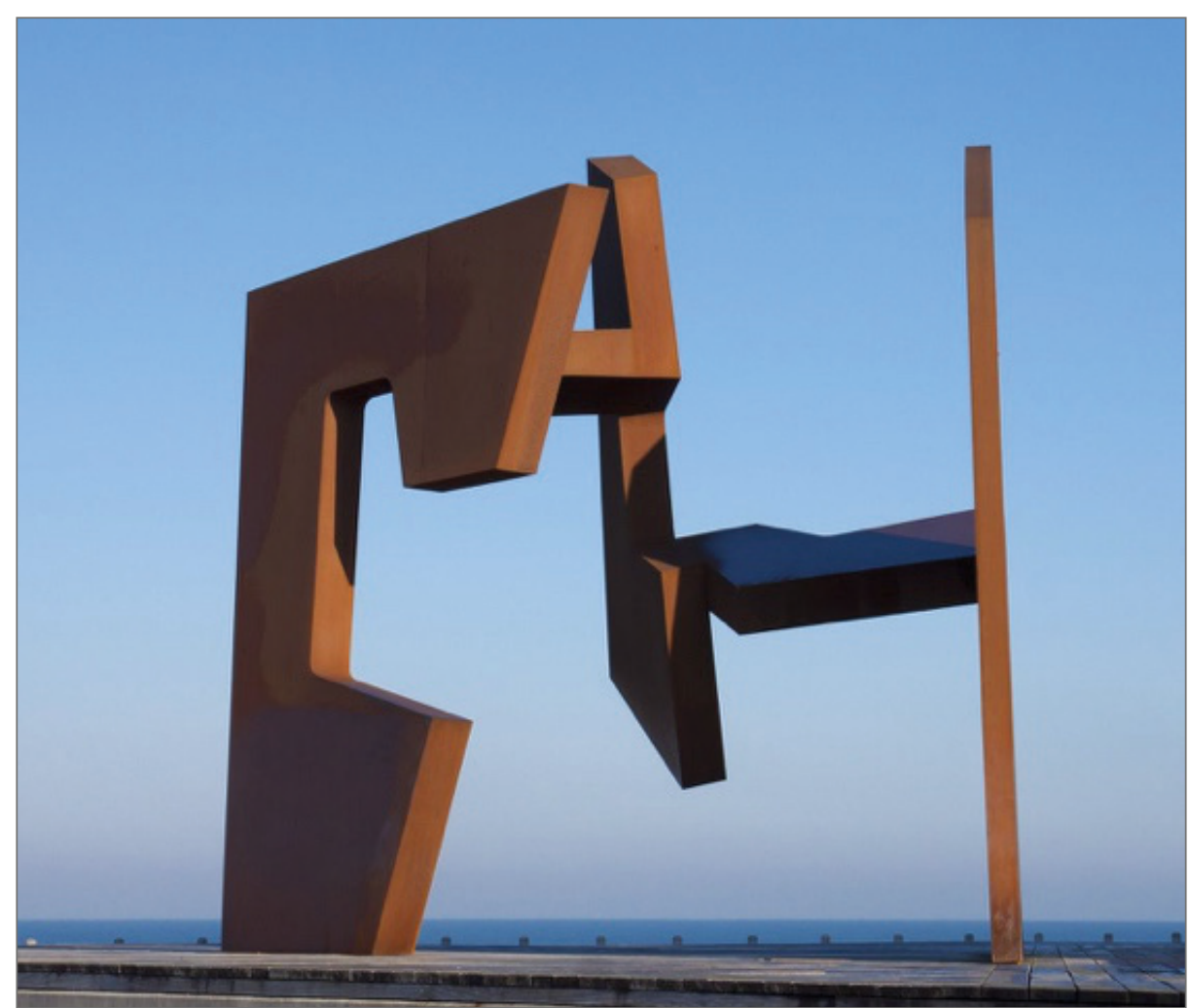

Figura 3. Jorge Oteiza, Primera variante. Vacíos en cadena / Construcción vacía con cuatro unidades planas positivo-negativo 2002, Obra original de 1957. Ampliación en San Sebastián de 2002. https://i.pinimg.com/originals/2e/9a/2d/2e9a2d7cf31482856be0f2fa1e5122f4.jpg

El arte público de Oteiza contendría arquetipos de transformación que ayudarían a los habitantes de la ciudad a buscar una unificación y armonía perdida, pues como dice el propio escultor, el arte nos obligaría a poner en juego nues- 
tras "reservas espirituales, a enriquecerlas. Podemos hablar estéticamente de curación espiritual" (citado en Kortadi 2005, 46). Esta unificación de nuestro mundo interior y exterior estará presente en numerosas ocasiones en su obra como podemos ver en Primera variante. Vacíos en cadena / Construcción vacía con cuatro unidades planas positivo-negativo, obra original de 1957 que se expuso en el conjunto con el que representaba a España en la Bienal de Sao Paulo de 1957, ganando en la modalidad de Escultura, esta obra fue posteriormente ampliada para colocarla en San Sebastián en 2002 (Fig. 3). En esta obra trabaja con los contrarios, espacio y tiempo, lo que podría concebirse en relación con el yin y el yang chinos que designarían de modo universal la dualidad y el complementarismo cómo dice el I Ching o Libro de las Mutaciones que considera como principios esenciales del universo, lo femenino y lo masculino. L. Yanchi (citado en Duch 2002, 324) señala cómo la teoría del yin y del yang describiría un proceso de fenómenos que tendrían cualidades opuestas que interactuarían para formar una totalidad integrada, de forma que la salud del ser humano se mantendría por un consumo y soporte continúo del yin y el yang que produciría "un equilibrio dinámico en el cuerpo. Si esta armonía se modifica, ya sea por una carencia o por un exceso de yin o yang, entonces irrumpe un estado de enfermedad".

Oteiza llevará a su concepto de arte público las "zonas-grises" que compara con el jardín japonés, espacio que en Extremo Oriente tiene un significado místico como vemos en sus comentarios sobre la imagen fotográfica de Eraso (Navarra) titulada "Frontón para juego de pelota" de su libro Quousque Tandem...!, donde el escultor escribe como estos espacios en las grandes ciudades congestionadas constituirían estéticamente zonas destinadas a la sensibilización y el 'aislamiento metafísico' (Oteiza [1963] 2021, 58-66) como si fueran construcciones-cromlench o "como los jardines de piedra de Kyoto" (ibíd., 58-66). Para Oteiza el cromlech poseería una protección primitiva y colectiva a la que denomina 'cromlech-ciudad', como elemento de integración del individuo en la colectividad del grupo que materializa en su proyecto que no llegó a realizarse titulado el Monumento a José Batlle y Ordóñez en Montevideo, obra que presentó junto al arquitecto Roberto Puig en concurso público en 1957. En este proyecto el escultor llevará a escala arquitectónica su descubrimiento del cromlech, señalando cómo esta obra sería un nuevo concepto de monumento para "la reflexión íntima de la persona" (Oteiza [1963] 2021, 103). Los autores partieron del concepto de la desocupación espacial para trasmitir en el espectador un sentimiento sagrado al situarlo en un espacio central:

Los tres elementos materiales del proyecto, el cuadrado negro, el muro y el edificio, tienen su correspondiente espacio-activo. 
Así, el cuadrado negro activa un cubo espacial; el muro que parte del edificio y se prolonga hasta el cuadrado negro activa un plano espacial; y el edificio activa su espacio envolvente.

(López Bahut 2007, 22)

El Monumento a José Batlle y Ordóñez sería según Oteiza una respuesta a Sigfried Giedion, cuando éste pregunta: “¿Cuál sería el tipo de monumentalidad que correspondería al arte de nuestro tiempo?” (Oteiza [1963] 2021, 103), contestando al historiador suizo de la arquitectura como este proyecto sería "una conclusión espacialmente desocupada como definición desde lo estético de un espacio religioso de idéntica naturaleza a la de nuestro crómlech" (ibíd.). En esta obra volvemos a encontrar proyectado el simbolismo de la unión de los contrarios ya que en la maqueta además de presentar materialmente como quedaría el monumento, adjuntaron un fotomontaje donde aparecía simultáneamente "lo visible y lo invisible, la forma y el espacio activo del conjunto, aquel que se ha obtenido al desocuparlo formalmente" (López Bahut 2007, 22).

Oteiza afirmaba que el ser humano necesitaría "ampliar su libertad y tomar posesión de la verdad, del milagro visual incesante que envuelve su vida. De esta educación trata el arte porque su finalidad es la salvación espiritual del hombre" (citado en Kortadi 2005, 46), llamando la atención de la sociedad de cómo el arte tendría la misión de enriquecer la sensibilidad del ser humano y "de transformar al hombre en una clase espiritual superior" (ibíd., 39). Sobre su obra titulada Ensayo en partición del vacío en horizontal por oposición de dos diedros explica estas vivencias:

Cuando concluí en la Nada activa de mis Cajas vacías, pensé si podría ir más lejos. Dividirla, como para abrirla más, ensayé primero en vertical, esta luego en horizontal, 1959, y creo que como sentimiento espacial es lo más puro que he logrado (para un parque o un espacio-iglesia) como dos manos sembrando, o como partiendo el pan, sí, podría simbolizar la Última Cena, Cristo partiendo el pan.

(Oteiza citado en Kortadi 2005, 45)

Sri Aurobindo vaticina la llegada de un idealismo subjetivo, que tras el reinado del individualismo y del intelectualismo objetivo, aplicará sus principios a las cuestiones sociales, siendo el artista un elemento clave en esta nueva era que comienza, donde el ser humano empezará a ser más intuitivo, rompiendo con nuestras clasificaciones del mundo y de nuestro propio yo, destruyendo esos muros demasiado rígidos de la realidad y abriendo al ser humano nuevas vías 
de comunicación. Aquí el arte de la ciudad puede acercar al público en general a una nueva simbología relacionada con nuestro futuro evolutivo pues como decía Oteiza, el arte tiene que estar al servicio del ser humano y de su destino: "el arte o es salvación o no es nada" (citado en Kortadi 2005, 104).

\section{CONCLUSIONES}

Los arquetipos presentes en la escultura de Oteiza funcionarían en la consciencia, del espectador, actuando como elementos transformadores colectivos y modificando la sociedad como impulsores de la consciencia colectiva de los habitantes de la ciudad. Este proceso tendría concomitancias con los procesos psicológicos de la filosofía Zen poniendo en marcha nuestra subjetividad a través de una simbología relacionada con un conocimiento por identidad, que tendría que ver con una unidad profunda de la existencia frente a nuestro conocimiento mental, que operaría fuera de nosotros mediante la división y el juicio racional.

La geometría y el símbolo en la escultura de Oteiza se pueden convertir en un puente de conexión entre nuestro pasado y nuestro futuro evolutivo, siendo elementos no sólo de memorización de nuestra historia, sino que también se convierten en nuevos símbolos por descubrir, relacionados con nuestro universo interior, organizando la armonía de nuestra existencia en principios eternos y produciendo una curación espiritual, lo que supondría una renovación del ser humano, devolviéndonos a nuestras raíces.

\section{Referencias bibliográficas}

Álvarez Martínez, María Soledad. 2008. Jorge Oteiza: Pasión y razón. San Sebastián: Nerea Arnaiz Gómez, Ana. 2006. "Entre escultura y monumento: La estela del Padre Donostia para Agiña del escultor Jorge Oteiza". Ondare 25: 305-25

Aurobindo, Sri. (1949) 2008. La evolución espiritual. Traducción, Pilar Nieto Carrillo. Barcelona: Fundación Centro Sri Aurobindo

Aurobindo, Sri. (1949) 2002. El ciclo humano. Traductores, María Tabuyo \& Agustín López; revisión, Kevala. Barcelona: Fundación Centro Sri Aurobindo

Aurobindo, Sri. (1921) 2005. Síntesis del yoga, Primera parte: Yoga de las obras divinas. Versión española de la tercera edición en ingles por Hector V. Morel. Buenos Aires: Kier 
Aurobindo, Sri. (1921) 2001. El secreto del veda. Traducción, Agustín López; corrección de textos, Félix

Aurobindo, Sri. (1921) 1980. Síntesis del yoga: Libro III: Yoga de autoperfección. Versión española de la tercera edición en ingles por Hector V. Morel. Buenos Aires: Kier

Aurobindo, Sri. (1909) 1999. La evolución futura del hombre. Traducido al español por Hortensia De la Torre. Barcelona: Fundación Centro Sri Aurobindo

Bachelard, Gaston. (1960) 2019. La poética de la ensoñación. Traducción de Ida Vitale. Ciudad de México: Fondo de Cultura Económica

Badiola, Txomin. 2004. "Desocupación de la esfera". En Oteiza: Mito y modernidad [Mitoa eta modernotasuna], textos, Margit Rowell \& Txomin Badiola, 199-233. Bilbao: Museo Guggenheim Bilbao

Cabañas Moreno, Pilar \& Matilde Rosa Arias Estévez. 2020. Zen, Tao y Ukiyo-e: Horizontes de inspiración artística contemporánea. Gijón: Satori

Chopra, Deepak \& Menas Kafatos. 2017. Tú eres el universo: Una nueva alianza entre ciencia y espiritualidad, un nuevo futuro de posibilidades infinitas (Conciencia global). Trad., Alejandro Pareja Rodríguez. Madrid: Gaia

Cirlot Laporta, Juan-Eduardo. (1958) 1969. Diccionario de símbolos. Barcelona: Labor

Daniélou, Alain. (1935) 2012. Mientras los dioses juegan. Prólogo, Joscelyn Godwin; traducción, Antonio Rodríguez. Girona: Atalanta

Dorfles, Gillo. 1969. Nuevos ritos, nuevos mitos. Traducción de Alejandro Saderman. BarceIona: Lumen

Duch, Lluis. 2002. Antropología de la vida cotidiana: Simbolismo y salud. Madrid: Trotta

Hemenway, Priya. 2008. El código secreto: La misteriosa fórmula que rige el arte, la naturaleza y la ciencia. Barcelona: Evergreen

Juan de la Cruz, Santo. (1591) 1999. Poesías completas. Estudio preliminar, Luis Miguel Martín Santos. Madrid: Edimat

Jung, Carl Gustav. (1946) 1993. La psicología de la transferencia: Esclarecida por medio de una serie de imágenes de la alquimia; Para médicos y psicologos prácticos. Prólogo y notas de Enrique Butelman: versión castellana de J. Kogan Albert. Barcelona: Paidós

Kortadi Olano, Edorta. 2005. Oteiza, un genio proteico, un artista poliédrico. Donostia: Erein

Lao Tse. (ca. 300 a.C.) 1998. Tao te king. Versión de John C.H. Wu; traducción, Alfonso Colodrón. Madrid: Edaf

Lao Tse. (ca. 300 a.C.) 1996. Hhu ching: 81 meditaciones taoístas. Versión de Brian Walker. Madrid: Edaf

Lao Tse. (ca. 300 a.C.) 1995. Wen-Tzu: La comprensión de los misterios del Tao. Versión de Thomas Cleary; traducción al español de Alfonso Colodrón. Madrid: Edaf

Lawlor, Robert. (1982) 1993. Geometría sagrada: Filosofía y práctica. Versión castellana de María José García Ripoll. Madrid: Debate

López Bahut, Emma. 2007. De la escultura a la ciudad: Monumento a Batlle en Montevideo; Oteiza y Puig, 1958-60. Alzuza: Fundación Museo Jorge Oteiza 
Macareno Ramos, Jon. 2017. Laboratorios experimentales del escultor Jorge Oteiza y el psiquiatra Carl Gustav Jung: La operación simbólica en la construcción del tejido sujeto-comunidad. Alzuza: Fundación Museo Jorge Oteiza

Oteiza, Jorge. 1988. Cartas al príncipe. Zarautz: Itxaropena

Oteiza, Jorge. (1995) 2017. Mentalidad vasca. Introducción de José Julián Baquedano. Pamplona: Pamiela

Oteiza, Jorge. (1990) 2019. Existe Dios al noroeste. Pamplona: Pamiela

Oteiza, Jorge. (1963) 2021. Quousque tandem...! Ensayo de interpretación estética del alma vasca, su origen en el cromlech neolítico y su restablecimiento por el arte contemporáneo. Pamplona: Pamiela

Oteiza, Jorge. (1952) 2007. Interpretación estética de la estatuaria megalítica americana: Carta a los artistas de América; Sobre el arte nuevo en la postguerra. Coord. y responsable de la edición, María Teresa Muñoz en colaboración con Joaquín Lizasoain \& Antonio Rubio; traductor al euskera, Pello Zabaleta Kortaberria. Alzuza: Fundación Museo Jorge Oteiza

Pérez de Carrera, Eduardo. 2004. 49 respuestas a la aventura del pensamiento. Madrid: Argos

Vega Esquerra, Amador. 2005. "Mística y pensamiento de Jorge Oteiza”. En Oteiza: Mito y modernidad [Mitoa eta modernotasuna], textos, Margit Rowell \& Txomin Badiola, 65-83. Bilbao: Museo Guggenheim Bilbao

Weyl, Hermann. (1938) 1990. Simetría. Traductor Lorenzo Abellanas Rapun. Madrid: Graw-Hill

Wilczek, Frank. (2008) 2018. La ligereza del ser: Masa, éter y la unificación de las fuerzas. Traducción castellana de Rosa M. Salleras Puig. Barcelona: Crítica 